\section{ERCP for the treatment of traumatic biliobronchial and biliocutaneous fistulas}

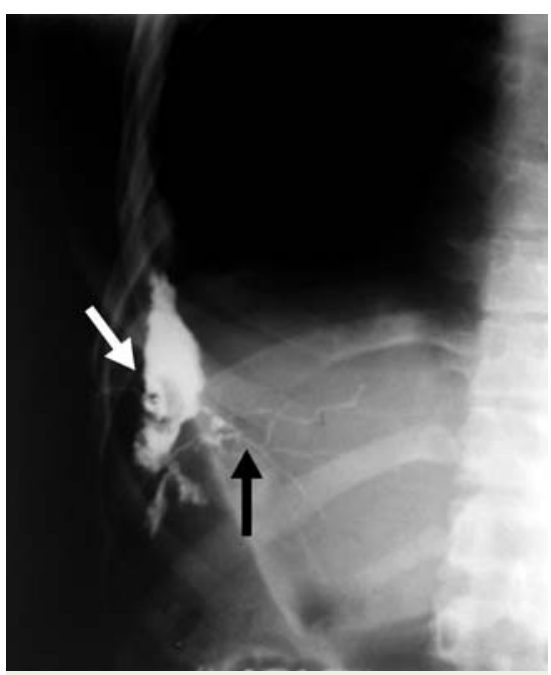

Fig. 1 Fistulogram demonstrating pooling of contrast (white arrow) around the right costophrenic angle, communicating with the liver laceration. Multiple intrahepatic ducts are also visualized (black arrow).

A 21-year-old man presented to casualty following a roadside bomb blast. A traumatic pneumothorax necessitated the insertion of a chest drain, and a laparotomy revealed multiple liver lacerations and ureteric contusion. While the patient was awaiting further ureteric surgery after a percutaneous nephrostomy, the chest drain was removed. One week later, limegreen serosanguinous fluid began to leak from the drain site, while the patient began to cough up bitter yellow sputum. Biochemical analysis of these fluids con- firmed the presence of bilirubin, suggesting the possibility of thoracobiliary fistulas involving the airways and pleural cavity. Ultrasound and computed tomography (CT) scans delineated a single biliocutaneous fistula, which was surgically excised. However, because the bilioptysis and bile leakage persisted, a fistulogram $(\bullet$ Fig. 1 ) and contrast CT scan ( $\bullet$ Fig. 2) were undertaken; these revealed multiple biliocutaneous and biliobronchial fistulas. Due to the patient's ongoing recovery from complex major surgery, a conservative approach involving endoscopic retrograde cholangiopancreatography (ERCP) with sphincterotomy and stenting was adopted. The ERCP findings were normal (i.e. revealing no contrast leakage), but the procedure resulted in the complete cessation of bilioptysis and of cutaneous bile leakage (i.e. from $500 \mathrm{ml} /$ day to nil) over 1 week. The patient thereafter remained fully asymptomatic from the thoracobiliary trauma.

Biliopleural and biliobronchial fistulas are hitherto unreported complications of blast injuries [1]. Regardless of etiology, the rare biliopleural and biliobronchial fistulas are diagnosed on finding bile in the pleural cavity, by thoracocentesis, or in a sputum sample [2,3]. Nonoperative fistula resolution may be attempted by distally decompressing the biliary system either surgically or endoscopically; the latter offers both diagnostic and therapeutic potential with a single minimally

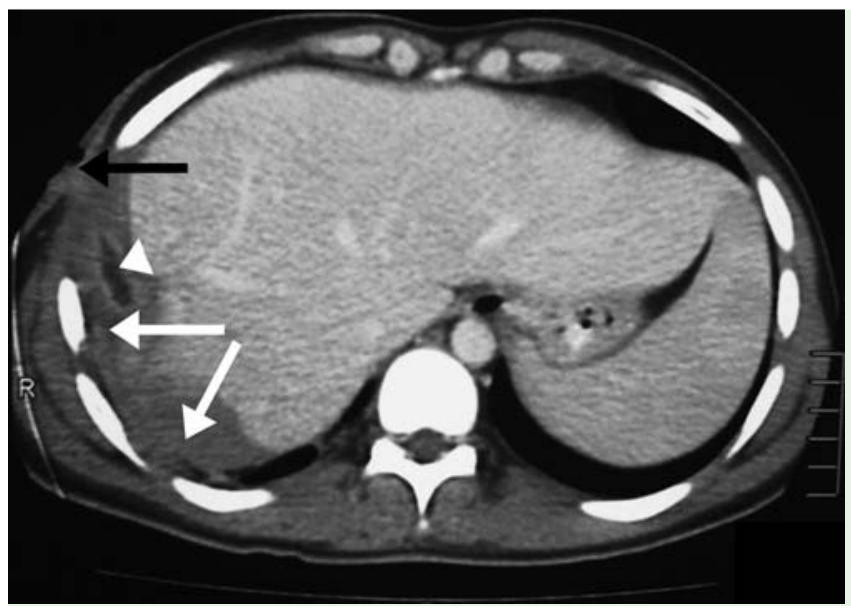

Fig. 2 Contrast computed tomography (CT) scan of the abdomen demonstrating a bilioma in the right hepatic lobe (white arrows) and one of many biliocutaneous tracts leading to a defect in the skin (black arrow). Air is demonstrated within the bilioma (white arrowhead) as part of the tract. traumatic procedure $[4,5]$. We recommend that even without evidence of biliary hypertension (i.e. if imaging excludes bile duct dilatation), ERCP with sphincterotomy and stenting is considered in patients like ours who have complex refractory pathology or are unfit for surgery. The relatively minor procedure may significantly reduce retrograde bile flow, resulting in major symptomatic improvement, before riskier alternatives (e.g. laparotomy or thoracotomy) are considered.

\section{Endoscopy_UCTN_Code_TTT_1AR_2AG}

\section{Competing interests: None}

\section{S. G. Thrumurthy ${ }^{1,2}$, A. H. M. P. Anurud-} dha ${ }^{1}$, M. I. M. De Zoysa ${ }^{1}$, D. N. Samarasekera ${ }^{1}$

1 University Surgical Unit, National Hospital of Sri Lanka, Colombo 10, Sri Lanka

2 Department of General Surgery, Royal Preston Hospital, Lancashire Teaching Hospitals NHS Foundation Trust, Preston, PR2 9HT, UK

\section{References}

1 Wolf SJ, Bebarta VS, Bonnett CJ et al. Blast injuries. Lancet 2009; 374: 405-415

2 Lewis JR, Te HS, Gehlbach B et al. A case of biliopleural fistula in a patient with hepatocellular carcinoma. Nat Rev Gastroenterol Hepatol 2009; 6: 248-251

3 Pende V, Marchese M, Mutignani M et al. Endoscopic management of biliopleural fistula and biloma after percutaneous radiofrequency ablation of liver metastasis. Gastrointest Endosc 2007; 66: 616-618

4 Chua HK et al. Bronchobiliary fistula: principles of management. Ann Thorac Surg 2000; 70: $1392-1394$

5 Singh B, Moodley J, Sheik-Gafoor MH et al. Conservative management of thoracobiliary fistula. Ann Thorac Surg 2002; 73: $1088-$ 1091

Bibliography

DOI $10.1055 / \mathrm{s}-0030-1255898$

Endoscopy 2011; 43: E42

(c) Georg Thieme Verlag KG Stuttgart · New York . ISSN 0013-726X

Corresponding author

S. G. Thrumurthy, MBChB (Hons)

Department of General Surgery

Royal Preston Hospital

Lancashire Teaching Hospitals

NHS Foundation Trust

Preston

PR2 9HT

UK

Fax: +44-1257-245495

srigan@doctors.org.uk 